\title{
ZIF-67 Derived Co Nanoparticles Embedded N- Doped Mesoporous Carbon Nanocages as an Active Heterogeneous Fenton Catalyst for the Degradation of Tetracycline
}

Qian Wang ( $\sim$ drifting_leaf@126.com )

Xi'an Technological University

Xiaofei Wang

Shaanxi University of Science and Technology

Huairu He

Xi'an Technological University

\section{Research Article}

Keywords: HCo@NC, Fenton, Antibiotic wastewater, catalysis, degradation mechanism

Posted Date: May 6th, 2021

DOI: https://doi.org/10.21203/rs.3.rs-333220/v1

License: (c) (i) This work is licensed under a Creative Commons Attribution 4.0 International License.

Read Full License 
1 ZIF-67 derived Co nanoparticles embedded N-doped mesoporous carbon

2 nanocages as an active heterogeneous Fenton catalyst for the degradation

4 Qian Wang ${ }^{\mathrm{a}, *}$, Xiaofei Wang ${ }^{\mathrm{b}, *}$, Huairu $\mathrm{He}^{\mathrm{a}}$

5 a School of Materials Science and Chemical Engineering, Xi'an Technological

6 University, Xi'an, 710021, P. R. China.

7 b School of Materials Science and Engineering, Shaanxi University of Science

8 and Technology, Xi'an, 710021, P. R. China.

9 *Corresponding authors:

10 Dr. Qian Wang:

11 School of Materials Science and Chemical Engineering, Xi'an Technological 12 University, Xi'an, 710021, P. R. China.

13 E-mail: drifting_leaf@126.com

14 Dr. Xiaofei Wang:

15 School of Materials Science and Engineering, Shaanxi University of Science and Technology, Xi'an, 710021, P. R. China.

E-mail: wangxiaof@sust.edu.cn 


\section{Abstract}

Herein, the novel application of ZIF-67 derived HCo@NC as a highly active and stable catalyst for Fenton treatment of organic wastewater is discussed. The carbonization of the Cobalt based Zeolitic Imidazolate Framework-67 (ZIF-67) yielded of $\mathrm{HCo} @ \mathrm{NC} 700 \mathrm{~nm}$ shows a hollow structure inheriting the rhombic dodecahedron shape of the precusor ZIF-67. XPS analysis reveales the coexistence of $\mathrm{Co}^{2+}$ and $\mathrm{Co}^{0}$. The treatment of Tetracycline (TC) in $\mathrm{HCo} @ \mathrm{NC}$ catalyzed Fenton system indicates that hydroxyl radicals generated to oxidize TC to decompose, and the optimal condition is determined to be $0.71 \mathrm{mmol} \cdot \mathrm{L}^{-1} \mathrm{H}_{2} \mathrm{O}_{2}$ and $0.03 \mathrm{~g} \cdot \mathrm{L}^{-1}$ $\mathrm{HCo} @ \mathrm{NC}$ at $\mathrm{pH} 3$ for the treatment of $15 \mathrm{mg} \cdot \mathrm{L}^{-1} \mathrm{TC} . \mathrm{H}_{2} \mathrm{O}_{2}$ is catalyzed by $\mathrm{HCo} @ \mathrm{NC}$ to decompose to hydroxyl radicals for the degradation of $\mathrm{TC}$, and the reaction mechanism is proposed.

Keywords: HCo@NC; Fenton; Antibiotic wastewater; catalysis; degradation mechanism 


\section{Introduction}

There is no doubt that, the Fenton process is one of the most concerned technologies to deal with waters polluted by toxic, refractory organic pollutants, for its great effectiveness, as well as simplicity and low cost (Zhang et al., 2020). For its toxicity to people's health and its damage to biological diversity, antibiotic wastewater need to be treated urgently. Fenton process characterized by the generation of hydroxyl radicals $(\cdot \mathrm{OH})$, which is a strong oxidant with a potential of $1.90-2.80 \mathrm{eV}$ under neutral to acdic conditions, is the most attracktive technology trackling water pollution (Wang et al. 2020a; Zhou et al. 2020). The sciencetic fundermental of Fenton process is quite well known. But the wide application of traditional Fenton consist of ferrous ion and hydrogen peroxide is limited by its narrow $\mathrm{pH}$ window and the generation of iron sludge. The complex of industrial waste waters also gives a discount of the efficiency of Fenton process. In order to make the maximum utilization of Fenton, modifications are made, mainly in two ways. On the one hand, extra energies including light and electrocity are reported to be introduced in to assist Fenton reactions, the introduction of these energies improved the efficiencies of the degradation of pollutants, but also raise the cost of the reaction. On the other hand, efforts are committed to develop new solid catalysts. High catalytic potential and stability are considered essential for a good catalyst, and large surface area is considered important.

Co-content materials were reported many times to be of good photocatalytic potential, but the catalytic property of Co-content materials as a Fenton-like catalyst 
on the decomposition of $\mathrm{H}_{2} \mathrm{O}_{2}$ has rarely been reported. And usually, these materials are not uniform, and particle size is reported an important factor influencing the catalytic activity. Template-sacrifice method is considered eminent in preparing uniform catalysts (Wang et al. 2020b; Hou et al. 2020; Zhao et al. 2020). To obtain nanomaterials with specific morphology, large surface area and hollow structure, templates such as Metal Organic Frameworks (MOFs) were occupied (Liu et al. 2014; Han et al. 2018). As a series of porous MOFs, Zeolitic imidazolate framework (ZIF) are reported as templates or precursors for the fabrication of 3D hollow nanomaterials many times. ZIF as a series of porous crystalline material are reported to transform to three diamentional hollow nano-materials (Jiang et al. 2013). Porous N-dopped carbon nanocages derived from MOFs (Chaikittisilp et al. 2014; Salunkhe et al. 2016; Zhang et al. 2017; Han et al. 2017) commonly obtained from the process of calcination in inert atmosphere or in air. ZIF-67 consists of cobalt ion and organic metal framework is chosen as precusor to prepare the hollow Co-modified N-dopped porous carbon nanpcages in this study.

In this work, ZIF-67 was prepared using solution method as reported (Wang et al. 2020c) and occupied as precursor for the synthesis of the hollow Co-modified N-dopped porous carbon nanocages (HCo@NC). The large BET surface area and hollow structure provided it a large amount of active site for adsorption and catalysis, and catalytic reactions may be promoted by adsorption (Zhu et al. 2020; Wu et al. 2020; Duan et al. 2020). The HCo@NC obtained performed excellent in the degragdation of Tetracycline (TC), and batch experiments were carried out to explore 
the influence of factors on the catalytic behavior in Fenton-like system, including $\mathrm{pH}$, temperature, dosage of adsorbent and initial concentration of pollutant. The reactive oxygen species (ROS) play the dominated role in the AOPs are further elucidated by scavenger experimants and electron paramagnetic resonance (EPR) analysis. Finally, a possible reaction mechanism of the $\mathrm{HCo} @ \mathrm{NC} / \mathrm{H}_{2} \mathrm{O}_{2}$ Fenton-like system was proposed based on the experimental results and data analysis.

\section{Experimental section}

\subsection{Chemicals and Materials}

Polyvinyl pyrrolidone (PVP), $\mathrm{CoCl}_{2} \cdot 6 \mathrm{H}_{2} \mathrm{O}, 2$-methylimidazole, methanol, ethanol, $\mathrm{H}_{2} \mathrm{SO}_{4}, \mathrm{NaOH}$, Tetracycline, 5,5-dimethyl-1-pyrroline N-oxide (DMPO), KI and $\mathrm{NaN}_{3}$ were purchased from Aladdin, and used directly without purification.

\subsection{Synthesis of ZIF-67}

The preparation process of ZIF-67 was expounded systematically in Scheme 1, it was prepared according to previous report (Jiang et al. 2013). Synthesis of ZIF-67: $1.00 \mathrm{~g}$ polyvinyl pyrrolidone (PVP) and $1.04 \mathrm{~g} \mathrm{CoCl}_{2} \cdot 6 \mathrm{H}_{2} \mathrm{O}$ were uniformly dissolved in $80 \mathrm{~mL}$ methanol. After then, $80 \mathrm{~mL}$ methanol solution of $5.26 \mathrm{~g}$ 2-methylimidazole was ultrasonic added to the above solution for $5 \mathrm{~min}$. Afterwards, the mixture was stirred at room temperature for $1 \mathrm{~h}$ and aged for $24 \mathrm{~h}$. Finally, The solution obtained by centrifugation and washing was dried at $80^{\circ} \mathrm{C}$ for $12 \mathrm{~h}$.

\section{Scheme 1}

\subsection{Fabrication of $\mathrm{HCo} @ \mathrm{NC}$}

HCo@NC was obtained by directly carbonizing the precursor ZIF-67 in Ar 
100

101

102

103

104

105

106

107

108

109

110

111

112

atmosphere. ZIF-67 was firstly heated at the rate of $2^{\circ} \mathrm{C} \cdot \mathrm{min}^{-1}$ and kept at $350^{\circ} \mathrm{C}$ for $120 \mathrm{~min}$, and then heated at the rate of $5^{\circ} \mathrm{C} \cdot \mathrm{min}^{-1}$ and kept at the pyrolysis temperature of $700^{\circ} \mathrm{C}$ for $120 \mathrm{~min}$.

\subsection{Characterizations}

The crystal structure of precursors and the component of derivatives are analyzed by X-ray diffraction (XRD) (BRUKER D8, $\mathrm{Cu} \mathrm{K \alpha}$ at $40 \mathrm{kV}$ and $40 \mathrm{~mA}$ ). The morphology and structure are characterized by scanning electron microscope (SEM) (Quanta 400F) and transmission electron microscope (TEM) (JEM-2010), and the test acceleration voltage was $200 \mathrm{kV}$. The element composition is investigated by X-ray photoelectron spectroscopy (XPS) (PHI Quantera II ESCA System with Al Ka radiation at $1486.8 \mathrm{~V})$. Thermogravimetric analysis and differential thermal analysis (TGA/DSC, TGA/DSC1, Mettler Toledo) were simultaneously recorded. Conditions were flow rate of $50 \mathrm{~cm}^{3} \cdot \mathrm{min}^{-1}$, heating rate of $10^{\circ} \mathrm{C} \cdot \mathrm{min}^{-1}$ and argon atmosphere.

\subsection{Catalytic experiments}

To evaluate the catalytic performance of HCo@NC, TC was chosen as the target pollutant. All the degradation experiments were conducted in deionized water except radical quenching experiments. In a typical experiment, $200 \mathrm{~mL}$ of TC solution (20 $\mathrm{mg} \cdot \mathrm{L}^{-1}$ ) was added into a $500 \mathrm{~mL}$ of barker with $400 \mathrm{rpm}$ stirring, and then $8 \mathrm{mg}$ of catalyst was added into the above solution for $10 \mathrm{~min}$ to reach the absorption equilibrium. $\mathrm{NaOH}$ and $\mathrm{H}_{2} \mathrm{SO}_{4}$ solution were used to adjust the initial $\mathrm{pH}$ of system. Fenton reaction was initiated as $\mathrm{H}_{2} \mathrm{O}_{2}$ added, and samples were taken out for analyzing at predetermined time intervals. 

and $\mathrm{NaN}_{3}$ in the degradation system. Reactive oxygen species, played the dominant role, was further confirmed by electron paramagnetic resonance (EPR) experiments and DMPO and methanol were used as trapping agents were carried out.

\subsection{Electrochemistry tests}

The mixture of 90 wt\% HCo@NC and 10 wt\% PVDF was coated onto Ni foam, 


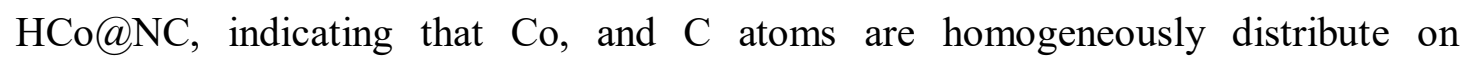
HCo@NC.

Figure 1

The content of $\mathrm{Co}$ in the obtained material is measured with thermogravimetric analysis (TGA) (Fig. 2). The weight loss from $215^{\circ} \mathrm{C}$ to $373^{\circ} \mathrm{C}(32.67 \%)$ is due to the pyrolysis of $\mathrm{N}$-dopped carbon. The exothermic peak in the heat flow curve at the corresponding region verified the combustion of $\mathrm{N}$-dopped carbon. The residual $67.34 \%$ weight is the contribution of cobalt.

\section{Figure 2}

XPS analysis is carried out to investigate surface compositions and the oxidation states of Co. The XPS spectra of fresh HCo@NC and HCo@NC after Fenton reaction are showed in Fig. 3. In the XPS survey spectrum of fresh HCo@NC, a set of peaks corresponding to $\mathrm{C} 1 \mathrm{~s}, \mathrm{~N} \mathrm{1s}, \mathrm{O} 1 \mathrm{~s}$, and Co $2 \mathrm{p}$ (Fig. 3a) are shown. In the high-resolution XPS spectra (Fig. 3b) of Co, Co 2p3/2 and Co 2p1/2 bands could be deconvoluted into three peaks corresponding to Co (0), Co (2+), and the shake-up (satellites) peak at $780.3,781.3,784.6 \mathrm{eV}$ and $794.7,796.5,804.4 \mathrm{eV}$, respectively. The appearance of $\mathrm{Co}(2+)$ might be resulted from the superficial cobalt oxide, for Co is susceptible to air ( $\mathrm{Li}$ et al. 2016a; Li et al. 2016b). The surface composition of $\mathrm{Co}(2+) / \mathrm{Co}(0)$ is calculated to be 0.553 , according to peaks areas (Table 1). A peak at $796.5 \mathrm{eV}$ ascribed to the $\mathrm{Co} 2 \mathrm{p} 1 / 2$ of the $\mathrm{Co}^{3+}$ ions appeared (Fig. 3c) (Wang et al. 2020d; Liu et al. 2020), and the surface composition of $\mathrm{Co}(2+) / \mathrm{Co}(3+)$ and $\mathrm{Co}(2+) / \mathrm{Co}(0)$ are calculated to be 7.128 and 0.607 , respectively (Table 1$)$. The 
increased proportion of $\mathrm{Co}(2+)$ and the generation of $\mathrm{Co}(3+)$ maybe ascribed to their catalysis behavior on the generation of hydroxyl radicals.

Figure 3

Table 1

\subsection{Catalytic mechanism}

An excellent catalyst is reported to be of good reversible redox character (Ai et al. 2008), which is usually analyzed using cyclic voltammetry tests, and the electron diffusion on the surface of catalyst is determine using AC impedance tests (Wang et al. 2013). The results are shown in Fig. 4(a) and Fig. 4(b). CV curve in Fig. 4(a) depicts the redox behavior of HCo@NC. Two pair of redox peaks could be observed (Fig. 4(b)) in the potential range for $\mathrm{HCo} @ \mathrm{NC}$ showing that the material is of good reversible redox character, and two electrons may transfer during the catalytic reaction (Ai et al. 2008), which may be due to the reversible transformation between $\mathrm{Co}^{2+}$ and $\mathrm{Co}^{0}$. From the EIS spectra shown in Fig. 4(b), the internal resistance of HCo@NC is determined to be $0.53 \Omega$, and the diffusion resistance calculated to be $0.48 \Omega$. Electrons are easy to diffuse during the catalytic process.

\section{Figure 4}

The catalytic performance of $\mathrm{HCo} @ \mathrm{NC}$ is evaluated by comparing the removal efficiencies of pollutants in different reaction systems (Fig. 5a) and the corresponding reaction rates are calculated (Fig. 5b). TC is selected as target organic pollutant for its toxicity and commonly seen. As shown in Fig. $5 \mathrm{a}, \mathrm{H}_{2} \mathrm{O}_{2}$ is too weak to oxidize TC to decompose (Wang et al. 2020e; Wang et al. 2021) $\left(1.291 \times 10^{-4} \mathrm{~min}^{-1}\right)$. The removal 
efficiency of $43.04 \%$ at $180 \mathrm{~min}$ in the presence of $\mathrm{HCo} @ \mathrm{NC}$ maybe caused by its hollow structure, and some TC molecules are adsorbed onto $\mathrm{HCo} @ \mathrm{NC}\left(5.67 \times 10^{-3}\right.$ $\left.\min ^{-1}\right) .99 .15 \%$ removal of TC can be obtained with the presence of $\mathrm{HCo} @ \mathrm{NC}+\mathrm{H}_{2} \mathrm{O}_{2}$, this may be due to the adsorption of $\mathrm{HCo} @ \mathrm{NC}$ and some generation of active radicals with strong oxidation potential. Active radicals generated in $\mathrm{HCo} @ \mathrm{NC} / \mathrm{H}_{2} \mathrm{O}_{2}$ system madeTC removed in a faster rate $\left(0.033 \mathrm{~min}^{-1}\right.$, Fig. $\left.5 b\right)$.

To further ascertain the primary active radicals for the degradation of TC, the quenching experiments are carried out. Hydroxyl radicals $(\cdot \mathrm{OH})$, superoxide anion radicals $\left(\mathrm{O}_{2} \cdot{ }^{-}\right)$are reported exist in Fenton-like process (Nie et al. 2020; Sun et al. 2020; Zhong et al. 2020). In this $\mathrm{HCo} @ \mathrm{NC} / \mathrm{H}_{2} \mathrm{O}_{2}$ Fenton-like system, the two active radicals mentioned above are detected, and $\mathrm{KI}$ is utilized to scavenge $\cdot \mathrm{OH}$ on the catalyst surface, and $\mathrm{NaN}_{3}$ is used as scavenger for oxygen and $\cdot \mathrm{OH}$ in solution. As shown in Fig. 5c, 99.15\% discoloration of TC can be obtained without any scavenger. When $\mathrm{NaN}_{3}$ is added to the $\mathrm{HCo} @ \mathrm{NC} / \mathrm{H}_{2} \mathrm{O}_{2}$ system, the discoloration efficiency of TC decreased from $93.3 \%$ to $85.5 \%$ at 180 min as the dosage of $\mathrm{NaN}_{3}$ increased from $0.03 \mathrm{mM}$ to $0.08 \mathrm{mM}$. As expected, the degradation efficiency of TC decrease from $99.15 \%$ to $53.2 \%$ with $0.03 \mathrm{mM} \mathrm{KI}$ added and the efficiency even decreased to $12.1 \%$ as the dosage of KI further increased to $0.08 \mathrm{mM}$. This phenomenon indicated that · $\mathrm{OH}$ radicals play a dominant role in $\mathrm{HCo} @ \mathrm{NC} / \mathrm{H}_{2} \mathrm{O}_{2}$ system, and ESR with DMPO is acquired to clarify the active radicals involved (Fig. 5d). No obvious $\mathrm{O}_{2}$ - $^{-}$ singals can be detected. However, four sharp signal peaks with the intensity ratio of 1:2:2:1 can be observed. The results indicated that, $\cdot \mathrm{OH}$ played the main role in the 
degradation of TC in $\mathrm{HCo} @ \mathrm{NC}$ catalyzed Fenton-like system.

Figure 5

According to the characterization and tests mentioned above, the possible degradation mechanism is put forward as follows (eqs 1-3) and proposed in Fig. 6. $\cdot \mathrm{OH}$ generated with the catalysis of HCo@NC for the degradation of TC.

$$
\mathrm{Co}+\mathrm{H}_{2} \mathrm{O}_{2} \rightarrow \cdot \mathrm{OH}+\mathrm{Co}^{2+}
$$

$$
\mathrm{Co}^{2+}+\mathrm{H}_{2} \mathrm{O}_{2} \rightarrow \cdot \mathrm{OH}+\mathrm{Co}^{3+}
$$

$$
\cdot \mathrm{OH}+\text { organics } \rightarrow \text { Intermediates } /\left(\mathrm{CO}_{2}+\mathrm{H}_{2} \mathrm{O}+\text { salt }\right)
$$

\section{Figure 6}

\subsection{Influence factors}

To investigate the optimal degradation condition, the Fenton-like system catalyzed by $\mathrm{HCo} @ \mathrm{NC}$ is evaluated under different initial pH, various dosages of catalyst and $\mathrm{H}_{2} \mathrm{O}_{2}$, and the results were presented in Fig. 7. As shown in Fig. 7(a), the degradation of TC increase as the initial solution $\mathrm{pH}$ increased from 2.02 to 2.98 . The most removal efficiency appeared at $\mathrm{pH} 2.98$, and $97.8 \%$ removal is achieved. As $\mathrm{pH}$ further increased from 2.98 to 7.95 , the removal efficiency reduced to $69.5 \%$ (especially sharply from $85.6 \%$ to $69.5 \%$ as $\mathrm{pH}$ increased from 7.02 to 7.95 ). Acidic conditions favor the production of reactive radicals, and hydroxyl radicals show higher oxidation potential $(2.80 \mathrm{eV})$ under acidic conditions than under neutral condition (1.90 eV) (Duan et al. 2020; Qu et al. 2020). Hydroxyl radicals generated may be scavenged by $\mathrm{H}^{+}$under strong acidic conditions, whereas the combination of $\mathrm{OH}$ - with active catalytic components $\left(\mathrm{Fe}^{2+}\right.$ and $\left.\mathrm{Fe}^{3+}\right)$ may inhibit the catalytic 
potential on radical production (Kuang et al. 2013; Xu et al. 2012). As shown in Fig. $7 \mathrm{~b}, 69.7 \%$ removal of TC is obtained with no catalyst present. Almost $100 \%$ removal of MB is obtained with catalyst added in our study. As the dosage of HCo@NC increased from $17.7 \mathrm{mg} \cdot \mathrm{L}^{-1}$ to $66.3 \mathrm{mg} \cdot \mathrm{L}^{-1}$, the degradation rate of TC increase, and then decrease as the dosage of $\mathrm{HCo} @ \mathrm{NC}$ further increased to $100 \mathrm{mg} \cdot \mathrm{L}^{-1}$. In Fig. 7c, as the dosage of $\mathrm{H}_{2} \mathrm{O}_{2}$ increased from 0.137 to $0.548 \mathrm{mmol} \cdot \mathrm{L}^{-1}$, the degradation efficiency of TC increase from $42.1 \%$ to $98.0 \%$, and decrease to $96.7 \%$ as the dosage of $\mathrm{H}_{2} \mathrm{O}_{2}$ further increased to $0.070 \mathrm{mmol} \cdot \mathrm{L}^{-1}$. This phenomenon is ascribed to the capture of hydroxyl radicals by $\mathrm{H}_{2} \mathrm{O}_{2}$. Reaction temperature is also considered significant parameter influencing a catalytic oxidation process. The effect of reaction temperature on the discoloration of TC at $\mathrm{pH} 3$ is tested $\left(\left[\mathrm{H}_{2} \mathrm{O}_{2}\right]=0.71 \mathrm{mmol} \mathrm{L}^{-1},[\mathrm{TC}]\right.$ $=15 \mathrm{mg} \mathrm{L}^{-1}$, catalyst dosage $=0.03 \mathrm{~g} \mathrm{~L}^{-1}$ and initial $\mathrm{pH}=3$;) and the result is depicted in Fig. 7d. Higher reaction temperature obviously avail the catalytic oxidation process. The reason maybe that $\mathrm{H}_{2} \mathrm{O}_{2}$ decomposes at a faster rate to generate more $\cdot \mathrm{OH}$ and more energy is provided to overcome reaction activated energy at higher temperature (Wang et al. 2014a; Wang et al. 2014b). Experimental plot data in the range of 0-30 min are fitted to a pseudo-second-order equation, and the coefficients $\mathrm{R}^{2}$ and $\mathrm{k}_{\mathrm{a}}$ are also listed in Table 2. Rate constants $\mathrm{k}_{\mathrm{a}}$ are $6.66 \times 10^{-3}, 7.11 \times 10^{-3}$, and $49.35 \times 10^{-3}$ $\min ^{-1}$ in correlation with reaction temperatures at 10,20 , and $30^{\circ} \mathrm{C}$. This phenomenon indicate that the reaction of TC degradation catalyzed by $\mathrm{HCo} @ \mathrm{NC}$ is favored at higher temperature and the reaction is endothermic.

Figure 7 
255 Kinetic studies of the degradation of TC are studied to quantitatively characterize the 256 removal of target pollutant under different conditions. It helps us to clarify the 257 relationship between influence factors and degradation of target pollutant and make 258 the activated reaction energy $\left(E_{\mathrm{a}}\right)$ clear. $E_{\mathrm{a}}$ can be calculated from the Arrhennius equation as listed in $\mathrm{Eq}(4)$ :

$\mathrm{k}_{a}=A \exp \left(\frac{-E_{a}}{R T}\right)$

261 The linear form of the equation is

$262 \ln \left(k_{\mathrm{a}}\right)=\ln (A)-\frac{E_{\mathrm{a}}}{R T}$

263

264

265

266

267

268

269

270

271

272

273

274

Are $k_{\mathrm{a}}$ the rate constant, A the preexponential factor, $E_{\mathrm{a}}$ the reaction activation energy ( $\mathrm{J} / \mathrm{mol}), R$ the gas constant $(8.314 \mathrm{~J} / \mathrm{mol} \mathrm{K})$, and $T$ the absolute temperature $(\mathrm{K})$. Using the data listed in Table $2, \ln \left(k_{\mathrm{a}}\right)$ versus $1 / T$ are plotted in Figure 8 , and $E_{\mathrm{a}}$ can be obtained from the slope of the linear fitted to the plots. The $E_{\mathrm{a}}$ value obtained in the case of the Fenton-like process catalyzed by HCo@NC was 73.05 kJ/mol.

Figure 8

\section{Conclusions}

A template method to prepare the nanomaterial HCo@NC with hollow structure as catalyst for the treatment of antibiotic wastewater has been put forward for the first time. HCo@NC as-prepared showed good catalytic behavior in the Fenton-like system, and $\cdot \mathrm{OH}$ generated on the surface of $\mathrm{HCo} @ \mathrm{NC}$ played the main role in the degradation of TC. $98 \%$ degradation of TC can be obtained with the presence of 66.3 
$\mathrm{mg} \cdot \mathrm{L}^{-1} \mathrm{HCo} @ \mathrm{NC}$ and $0.548 \mathrm{mmol} \cdot \mathrm{L}^{-1} \mathrm{H}_{2} \mathrm{O}_{2}$. The $E_{\text {a }}$ value obtained in the case of the Fenton-like process catalyzed by HCo@NC was 73.05 kJ/mol. In all, HCo@NC is a promising catalyst in Fenton-like process.

\section{Credit Author Statement}

Qian Wang: Supervision, Topic suggestion, Planning, Experimentation, Results analysis, Writing - main manuscript; Huairu He: Co-supervision, Project administration, Review \& editing; Xiaofei Wang: Co-supervision, Project administration, Review \& editing.

\section{Declaration of competing interest}

The authors declare that they have no known competing financial interests or personal relationships that could have appeared to influence the work reported in this paper.

Ethical Approval: Not applicable.

Consent to Participate: Not applicable.

Consent to Publish: Not applicable.

\section{Funding information}

The authors gratefully acknowledge the financial supporting by the National Natural Science Foundation of China (No. 51608412), the Natural Science Basic Research Plan in Shaanxi Province of China (No. 2019JQ-428), Young Talent fund of University Association for Science and Technology in Shaanxi, China (No. 20190607) the Special Fund Project of Education Department in Shaanxi Province of China (No. 19JK0409) and Chongqing Key Laboratory of Environmental Materials and 
Remediation Technology (Chongqing University of Arts and Sciences) (No.CEK1804), the Scientific Research Fund of Shaanxi University of Science and Technology (No. 2016BJ-48).

Availability of data and materials: Not applicable.

\section{REFERENCES}

Ai ZH, Xiao HY, Mei T, Liu J, Zhang LZ, Deng KJ, Qiu JR (2008) Electro-Fenton degradation of Rhodamine $\mathrm{B}$ based on a composite cathode of $\mathrm{Cu}_{2} \mathrm{O}$ nanocubes and carbon nanocubes. J Phys Chem 112:11929-11935. https://doi.org/10.1021/jp803243t.

Chaikittisilp W, Tord NL, Li C, Imura M, Suzuki N, Ishinsuke S, Ariga K, Yamauchi Y (2014) Synthesis of nanoporous carbon-cobalt-oxide hybrid electrocatalysts by thermal conversion of metal-organic frameworks. Chem Eur J 20:4217-4221. https://doi.org/10.1002/chem.201304404.

Duan Z, Zhang W, Lu M, Shao Z, Huang W, Li J, Li Y, Mo J, Li Y, Chen C (2020) Magnetic $\mathrm{Fe}_{3} \mathrm{O}_{4} /$ activated carbon for combined adsorption and Fenton oxidation of $\quad$ 4-chlorophenol. Carbon 167:351-363. https://doi.org/10.1016/j.carbon.2020.05.106.

Han B, Cheng G, Zhang E, Zhang L, Wang X (2018) Three dimensional hierarchically porous ZIF-8 derived carbon/LDH coreshell composite for high performance supercapacitors. Electrochim Acta 263:391-399. https://doi.org/10.1016/j.electacta.2017.12.175.

Han X, Sun L, Wang F, Sun D (2018) MOF-derived honeycomblike N-doped carbon structures assembled from mesoporous nanosheets with superior performance in lithium-ion batteries. J Mater Chem A 6:18891-18897. https://doi.org/10.1039/C8TA07682K. 
Hou S, Lian Y, Bai Y, Zhou Q, Ban C, Wang Z, Zhao J, Zhang H (2020) Hollow dodecahedral $\mathrm{Co}_{3} \mathrm{~S}_{4} @ \mathrm{NiO}$ derived from ZIF-67 for supercapacitor. Electrochim Acta 341:136053. https://doi.org/10.1016/j.electacta.2020.136053.

Jiang Z, Li Z, Qin Z, Sun H, Jiao X, Chen D (2013) LDH nanocages synthesized with MOF templates and their high performance as supercapacitors. Nanoscale 5: 11770-11775. https://doi.org/10.1039/c3nr03829g.

Liu Y, Wang N, Pan J, Steinbach F, Caro J (2014) In situ synthesis of MOF membranes on $\mathrm{ZnAl}-\mathrm{CO}_{3} \mathrm{LDH}$ buffer layer-modified substrates. J Am Chem Soc 136(41):14353-14356. https://doi.org/10.1021/ja507408s.

Kuang Y, Wang Q, Chen Z, Megharaj M, Naidu R (2013) Heterogeneous Fenton-like oxidation of monochlorobenzene using green synthesis of iron nanoparticles. $\mathrm{J}$ Colloid Interface Sci 410:61-73. https://doi.org/10.1016/j.jcis.2013.08.020.

Li X, Jiang Q, Dou S, Deng L, Huo J, Wang S (2016)a ZIF-67-derived Co-NC@CoP-NC nanopolyhedrals as efficient bifunctional oxygen

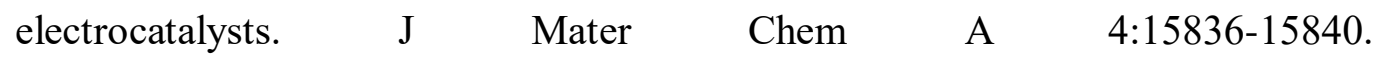
https://doi.org/10.1039/C6TA06434E.

Li X, Niu Z, Jiang J, Ai L (2016)b Cobalt nanoparticles embedded in porous N-rich carbon as an efficient bifunction electrocatalyst for water splitting. J Mater Chem A 4:3204-3209. https://doi.org/10.1039/C6TA00223D.

Liu Y, Wang B, Zhao Q, Yang S, Li Y, Zuo J, Wang H, Peng F (2020) A novel bicomponent $\mathrm{Co}_{3} \mathrm{~S}_{4} / \mathrm{Co} @ \mathrm{C}$ cocatalyst on $\mathrm{CdS}$, accelerating charge separation for highly efficient photocatalytic hydrogen evolution. Green Chem 22:238. https://doi.org/10.1039/C9GC03323H.

Nie M, Li Y, He J, Xie C, Wu Z, Sun B, Zhang K, Kong L, Liu J. (2020) Degradation of tetracycline in water using $\mathrm{Fe}_{3} \mathrm{O}_{4}$ nanospheres as Fenton-like catalysts: kinetics, 
mechanisms and pathways. New J Chem 44:2847-2857. https://doi.org/10.1039/D0NJ00125B.

Ouyang C, Wang X, Wang S. (2015) Phosphorus-doped $\mathrm{CoS}_{2}$ nanosheet arrays as ultra-efficient electrocatalysts for the hydrogen evolutionreaction. Chem Commun 51:14160-14163. https://doi.org/10.1039/c5cc05541e.

Qu, J., Yu, Z., Zang, Y., Gu, J., Jin, J., Gao, F., 2020. A CoMn $\mathrm{O}_{3.5}$-RGO hybrid as an effective Fenton-like catalyst for the decomposition of various dyes. Carbon 159:687. https://doi.org/10.1016/S1872-5805(19)60030-2.

Salunkhe RR, Tang J, Kamachi Y, Nakato T, Kim JH, Yamauchi Y. (2015) Asymmetric Supercapacitors Using 3D Nanoporous Carbon and Cobalt Oxide Electrodes Synthesized from a Single Metal-Organic Framework. Acs Nano 9(6): 6288-6296. https://doi.org/10.1021/acsnano.5b01790.

Salunkhe RR, Young C, Tang J, Takei T, Ide Y, Kobayashi N, Yamauchi Y. (2016) Correction: a high-performance supercapacitor cell based on ZIF-8-derived nanoporous carbon using an organic electrolyte. Chem Commun 52:4764-4767. https://doi.org/10.1039/C6CC90505F.

Sun F, Liu H, Wang H, Shu D, Chen T, Zou X, Huang F, Chen D. (2020) A novel discovery of a heterogeneous Fenton-like system based on natural siderite: A wide range of $\mathrm{pH}$ values from 3 to 9. Sci Total Environ 698:134293. https://doi.org/10.1016/j.scitotenv.2019.134293.

Wang G, Li Y, Xu L, Wang Y. (2020) Facile synthesis of difunctional NiV LDH@ZIF-67 p-n junction: Serve as prominent photocatalyst for hydrogen evolution and supercapacitor electrode as well. Renew Energ 162:535-549. https://doi.org/10.1016/j.renene.2020.08.053.

Wang Q, Tian S, Cun J, Ning P. (2013) Degradation of methylene blue using a 
heterogeneous Fenton process catalyzed by ferrocene. Desalin Water Treat 51(28-30):5821-5830. https://doi.org/10.1080/19443994.2012.763047.

Wang Q, Tian S, Ning P. (2014)a Degradation Mechanism of Methylene Blue in a Heterogeneous Fenton-like Reaction Catalyzed by Ferrocene, Ind Eng Chem Res 53(2): 643-649https://doi.org/10.1021/ie403402q.

Wang Q, Tian S, Ning P. (2014)b Ferrocene-Catalyzed Heterogeneous Fenton-like Degradation of Methylene Blue: Influence of Initial Solution pH. Ind Eng Chem Res 53(15): 6334-6340.https://doi.org/10.1021/ie500115j.

Wang Q, Wang X, He H. (2020)a In situ oxidation and simultaneous adsorptive removal of Arsenite by layered double hydroxide based solid hydrogen peroxide. J Hazard Mater 400:123045. https://doi.org/10.1016/j.jhazmat.2020.123045.

Wang Q, Wang X, He H, Chen W. (2020)c Fabrication of hollow LDH nanocages using ZIF-67 template as superb adsorbent for anionic organic pollutant. J. Porous Mat. https://doi.org/10.1007/s10934-020-01007-7.

Wang Q, Wang X, Liu S, Li R. (2020)e Efficient decolorization of Methylene Blue catalyzed by $\mathrm{MgFe}$-layered double hydroxides in the presence of hydrogen $\begin{array}{lllll}\text { peroxide. } & \text { Water } & \text { Sci } & \text { Technol } & \text { 81(4): }\end{array}$ https://doi.org/10.2166/wst.2020.161.

Wang Q, Wang X, Shi C. (2018) LDH nanoflower lantern derived from ZIF-67 and its application for adsorptive removal of organics from water. Ind Eng Chem Res 57(37): 12478-12484. https://doi.org/10.1021/acs.iecr.8b01324.

Wang W, Zhao W, Zhang H, Dou X, Shi H. (2021) 2D/2D step-scheme $\alpha-\mathrm{Fe}_{2} \mathrm{O}_{3} / \mathrm{Bi}_{2} \mathrm{WO}_{6}$ photocatalyst with efficient charge transfer for enhanced photo-Fenton catalytic activity. Chinese J Catal 42:97-106. https://doi.org/10.1016/S1872-2067(20)63602-6. 
Wang X, Liu H, Wang Q, Huo J, Ge W, Duan X, Guo S. (2020)d Microbial-derived functional carbon decorated hollow NiCo-LDHs nanoflowers as a highly efficient catalyst for $\mathrm{Li}-\mathrm{CO}_{2}$ battery. Appl. Surf. Sci. 540: 148351. https://doi.org/10.1016/j.apsusc.2020.148351.

Wu J, Lin M, Weng X, Owens G, Chen Z. (2020) Pre-adsorption and Fenton-like oxidation of mitoxantrone using hybrid green synthesized $\mathrm{rGO} / \mathrm{Fe}$ nanoparticles. Chem Eng J https://doi.org/10.1016/j.cej.2020.127273.

$\mathrm{Xu} \mathrm{L}$, Wang J. (2012) Fenton-like degradation of 2,4-dichlorophenol using $\mathrm{Fe}_{3} \mathrm{O}_{4}$ magnetic nanoparticles, Appl Catal B Environ 123-124: 117-126 https://doi.org/10.1016/j.apcatb.2012.04.028.

Zhang M, Xiao C, Yan X, Chen S, Wang C, Luo R, Qi J, Sun X, Wang L, Li J. (2020) Efficient removal of organic pollutants by metal-organic framework derived Co/C York-shell nanoreactors: Size-exclusion and confinement effect. Environ Sci Technol https://doi.org/10.1021/acs.est.0c00914.

Zhang W, Jiang X, Zhao Y, Carne-Sanchez A, Malgras V, Kim J, Kim JH, Wang S, Liu J, Jiang JS, Yamauchi Y, Hu M. (2017) Hollow carbon nanobubbles: monocrystalline MOF nanobubbles and their pyrolysis. Chem Sci 8: 3538-3546 https://doi.org/10.1039/C6SC04903F.

Zhao G, Xu X, Shi J, Li Y, Zhang S, Hossain S, Wu KC, Tang J, Yamauchi Y. (2020) Flexible nitrogen-doped carbon heteroarchitecyure derived from ZIF-8/ZIF-67 hydbrid coating on cotton biomass waste with high supercapacitive properties. Micropor Mesopor $\quad$ Mat

110257 https://doi.org/10.1016/j.micromeso.2020.110257.

Zhou Z, Li K, Deng W, Li J, Yan Y, Li Y, Quan X, Wang T. (2020) Nitrogen vacancy mediated exciton dissociation in carbon nitride nanosheets: Enhanced hydroxyl 
radicals generation for efficient photocatalytic degradation of organic pollutants. J Hazard Mater 387:122023. https://doi.org/10.1016/j.jhazmat.2020.122023.

424
Zhu Q, Yan J, Dai Q, Wu Q, Cai Y, Wu J, Wang X, Zhan W. (2020) Ethylene glycol assisted synthesis of hierarchical Fe-ZSM-5 nanorods assembled microsphere for adsorption Fenton degradation of chlorobenzene. J Hazard Mater 385: 121581. https://doi.org/10.1016/j.jhazmat.2019.121581.

Zhong X, Wu W, Jie H, Tang W, Chen D, Ruan T, Bai H. (2020) Degradation of norfloxacin by copper-doped $\mathrm{Bi}_{2} \mathrm{WO}_{6}$-induced sulfate radical-based visible $\begin{array}{lllll}\text { light-Fenton } & \text { reaction. } & \text { RSC } & \text { Adv } & 10:\end{array}$ https://doi.org/10.1039/D0RA07378D. 
434 Scheme 1 Synthetic procedure of HCo@NC 435 
437 Figure 1 (a) XRD pattern of HCo@NC (the inset is the XRD pattern of ZIF-67); (b)

TEM and (c) SEM images of ZIF-67; (d) TEM and (e) SEM images of HCo@NC; (f)

439 SEM image and elemental mapping results of $\mathrm{HCo} @ \mathrm{NC}$ : (g) elemental mapping 440 images of $\mathrm{C}$ and $\mathrm{Co}$ of the $\mathrm{HCo} @ \mathrm{NC}$.

441 Figure 2 The thermogravimetric analysis (TGA) curves of $\mathrm{HCo} @ \mathrm{NC}$

Figure 3 (a) Survey XPS spectra of HCo@NC; (b) Co 2p spectrum of HCo@NC

Figure 4 (a) CV curve of $\mathrm{HCo} @ \mathrm{NC}$ at $0.05 \mathrm{mV} \mathrm{s}-1$; (b) EIS spectra of $\mathrm{HCo} @ \mathrm{NC}$

444

445

446

447

448

449

450

451

452

453

454

455

Figure 5 (a) The removal efficiency of TC and (b) the rate constants under different conditions (Reaction condition: $\left[\mathrm{H}_{2} \mathrm{O}_{2}\right]=0.71 \mathrm{mmol} \mathrm{L}^{-1}$, [TC] $=15 \mathrm{mg} \mathrm{L}^{-1}$, catalyst dosage $=0.03 \mathrm{~g} \mathrm{~L}^{-1}$ and initial $\mathrm{pH}=3$ ); (c) the effects of different scavengers; (d) EPR spectra of $\mathrm{H}_{2} \mathrm{O}_{2}$ activation on $\mathrm{HCo@NC.}$

Figure 6 Possible mechanism of Fenton-like system catalyzed by HCo@NC

Figure 7 Effects of (a) initial solution $\mathrm{pH}$; (b) dosages of catalyst; (c) dosages of $\mathrm{H}_{2} \mathrm{O}_{2}$; (d) temperature on degradation of TC.

Figure 8 Plot of $\ln \left(k_{\mathrm{a}}\right)$ versus $1 / \mathrm{T}$ for the estimation of the reaction activated energy 
457 Table 1 Fitted parameters from XPS analysis of the HCo@NC

458 Table 2 Pseudo-second-order rate constants under different reaction temperatures 459 
461

462

463

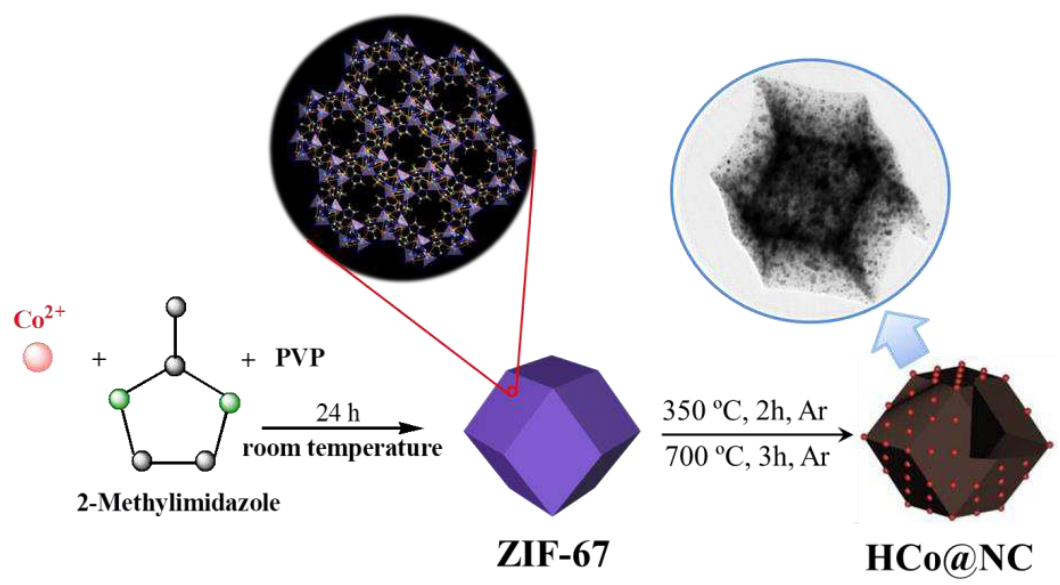

Scheme 1 

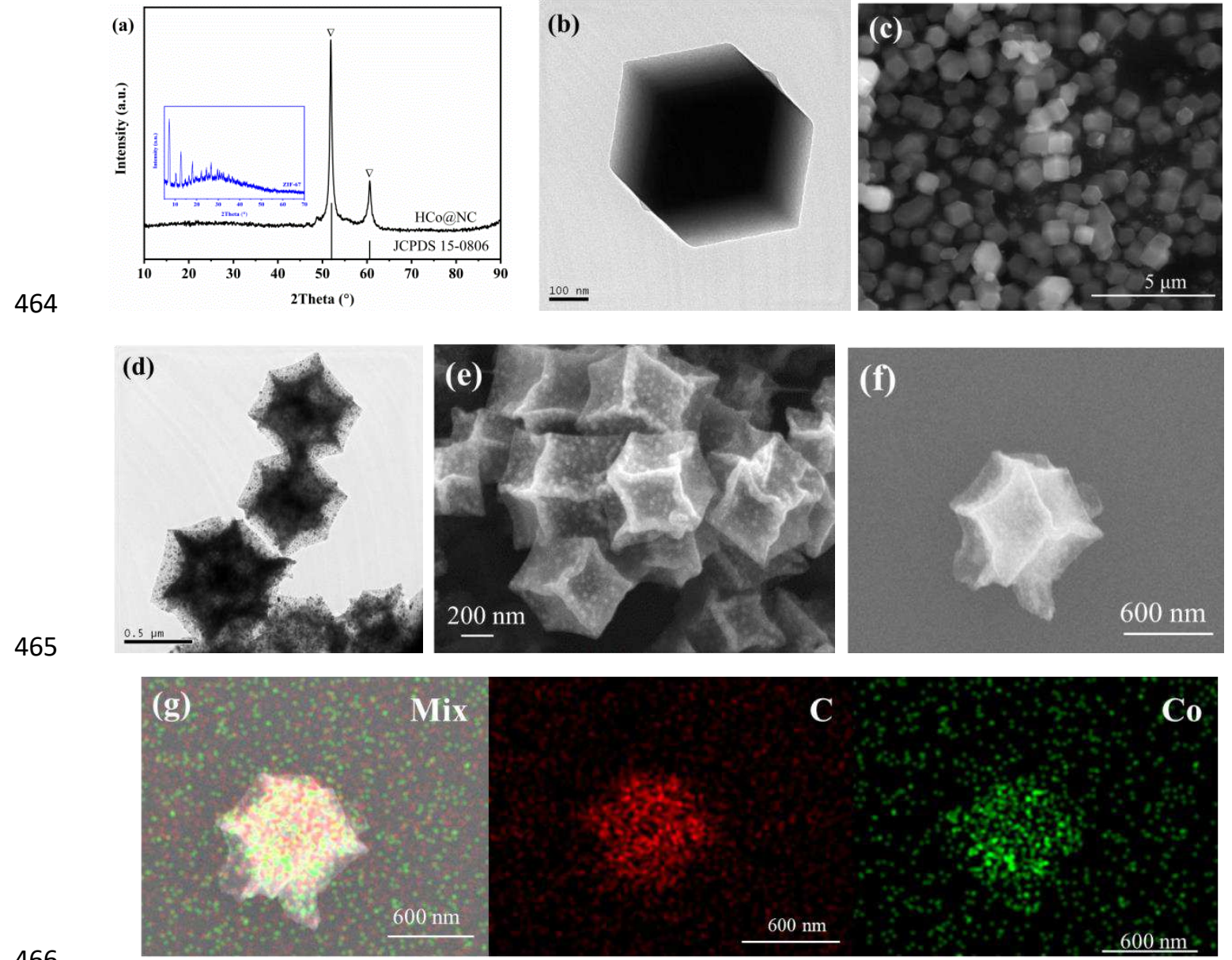

466

467

Figure 1

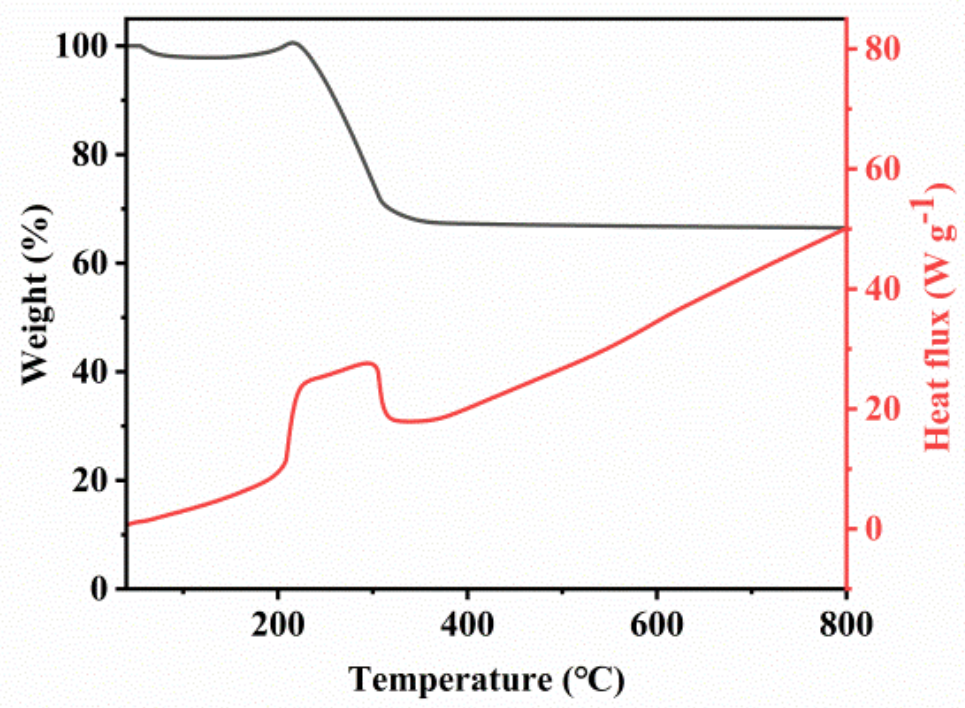

Figure 2 

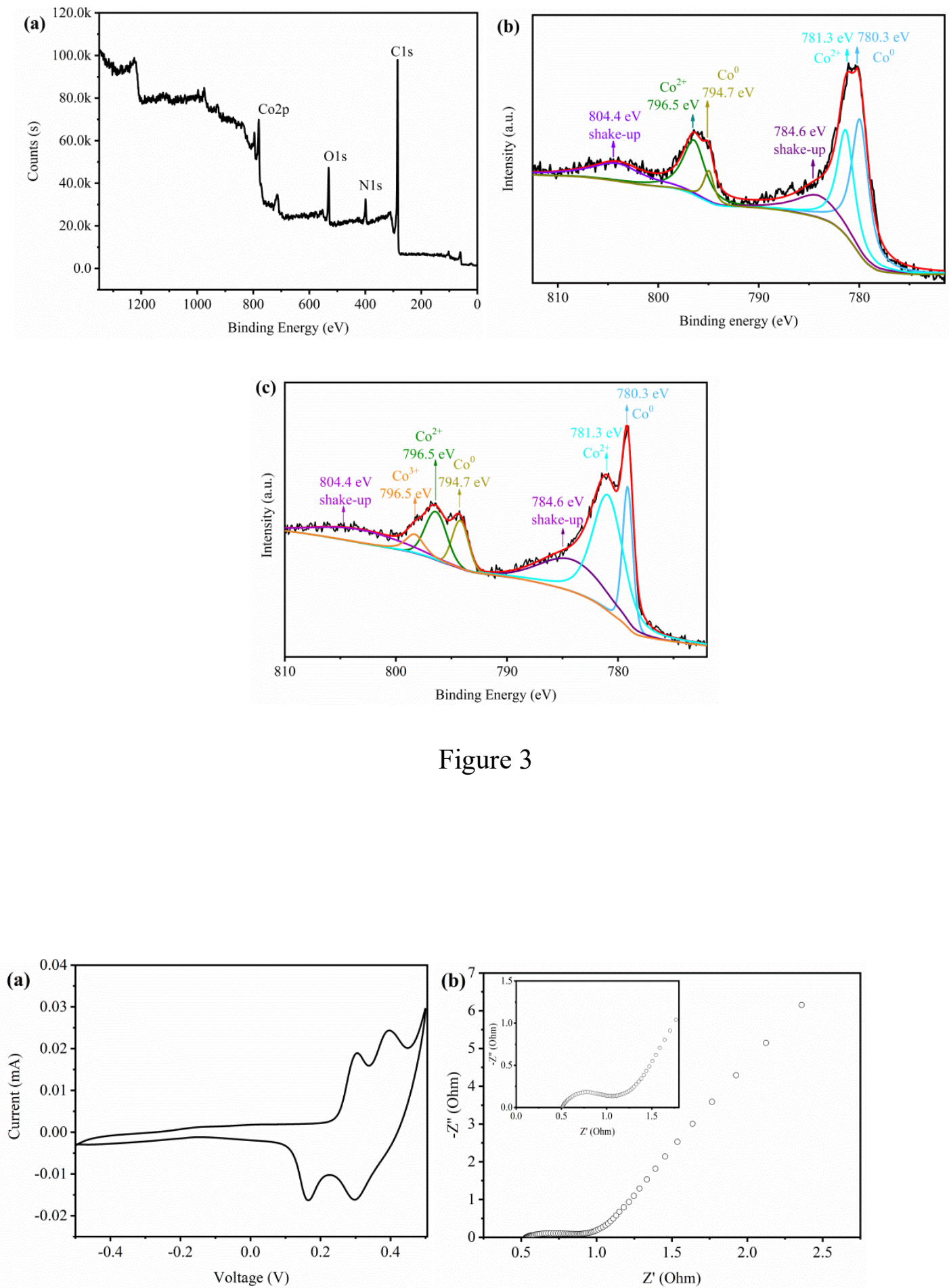

Figure 4 

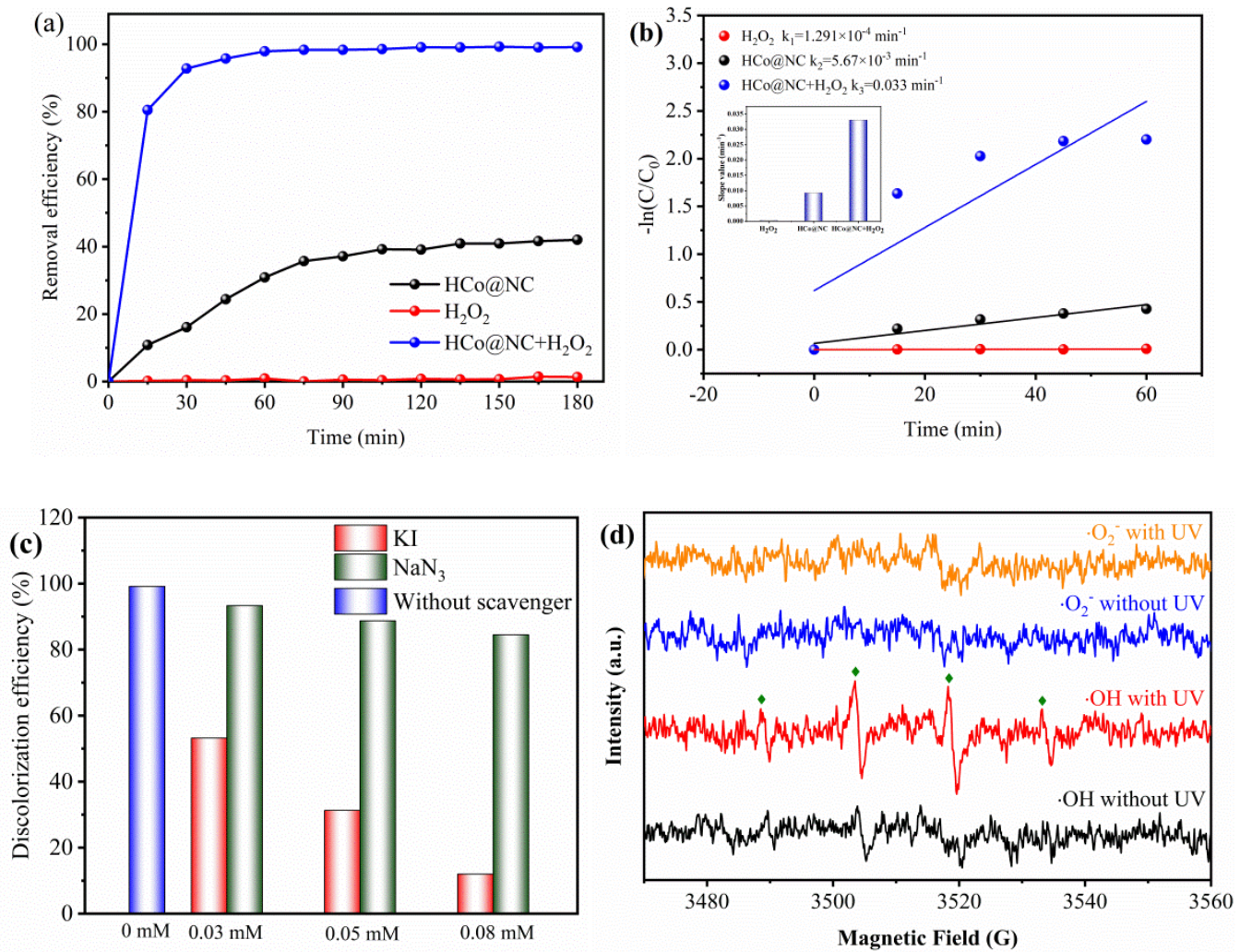

Figure 5

481

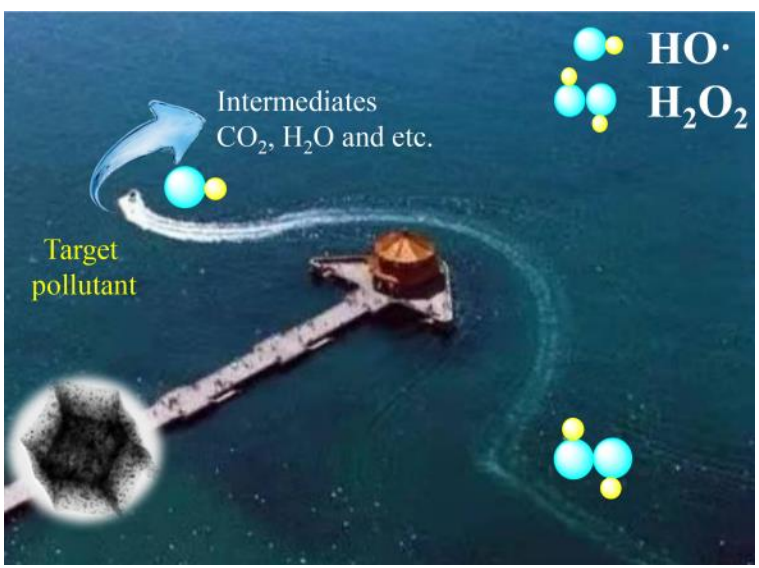

Figure 6 

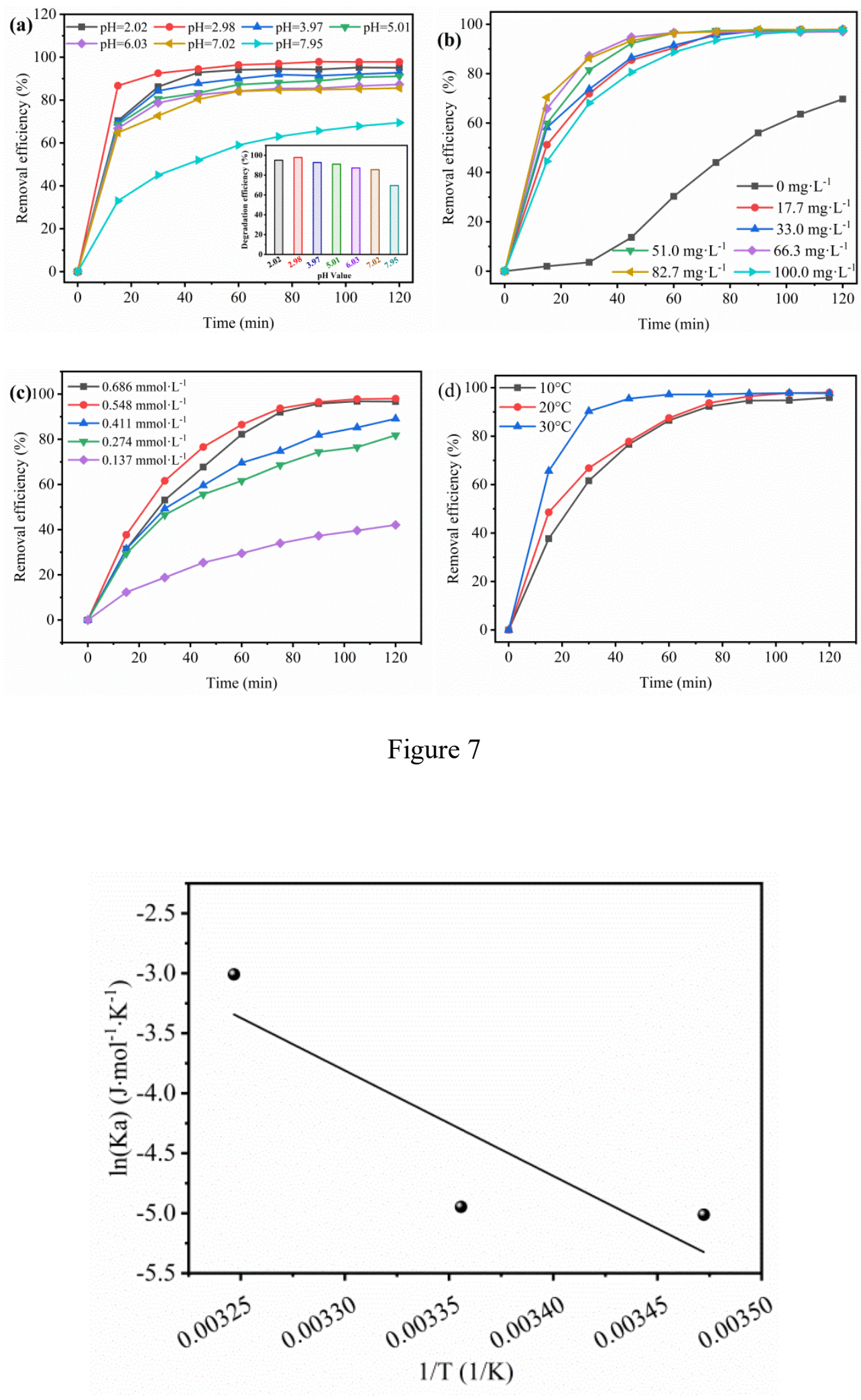
492

Table 1

\begin{tabular}{ccc}
\hline Materials & $\mathrm{Co}^{2+} / \mathrm{Co}^{3+}$ & $\mathrm{Co}^{2+} / \mathrm{Co}^{0}$ \\
\hline Fresh & - & 0.553 \\
$\mathrm{HCo} @ \mathrm{NC}$ & & \\
$\mathrm{HCo} @ \mathrm{NC}$ & 7.128 & 0.607 \\
after Fenton & & \\
reaction & & \\
\hline
\end{tabular}

493

494

Table 2

\begin{tabular}{ccc}
\hline Condition & $\mathrm{K}_{\mathrm{a}}, \mathrm{min}^{-1}$ & $\mathrm{R}^{2}$ \\
\hline $10^{\circ} \mathrm{C}(283 \mathrm{~K})$ & 0.00666 & 0.915 \\
$20^{\circ} \mathrm{C}(293 \mathrm{~K})$ & 0.00711 & 0.892 \\
$30^{\circ} \mathrm{C}(303 \mathrm{~K})$ & 0.04935 & 0.903 \\
\hline
\end{tabular}

495 


\section{Figures}
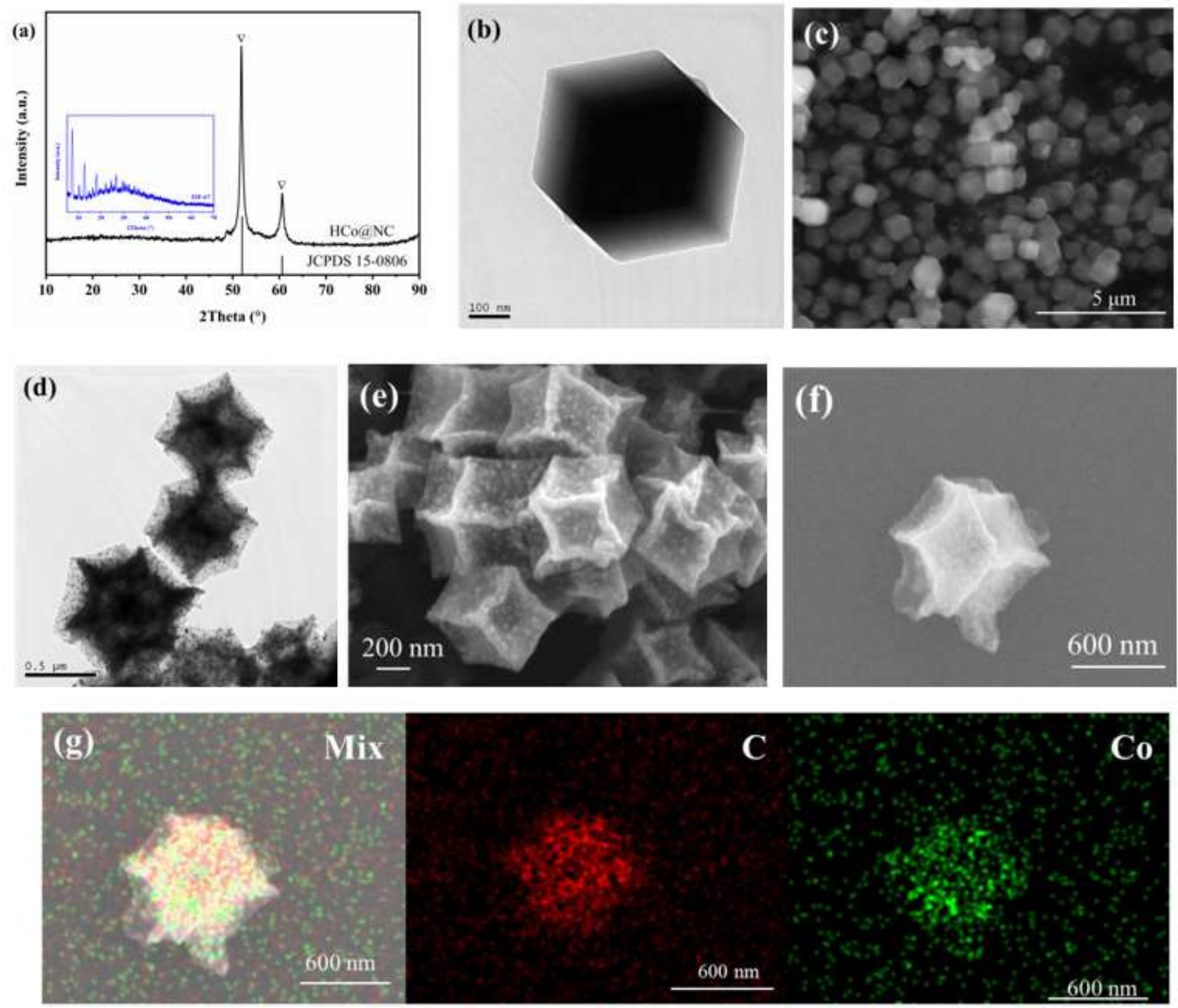

\section{Figure 1}

(a) XRD pattern of HCo@NC (the inset is the XRD pattern of ZIF-67); (b) TEM and (c) SEM images of ZIF67; (d) TEM and (e) SEM images of HCo@NC; (f) SEM image and elemental mapping results of HCo@NC: (g) elemental mapping images of $\mathrm{C}$ and $\mathrm{Co}$ of the HCo@NC. 


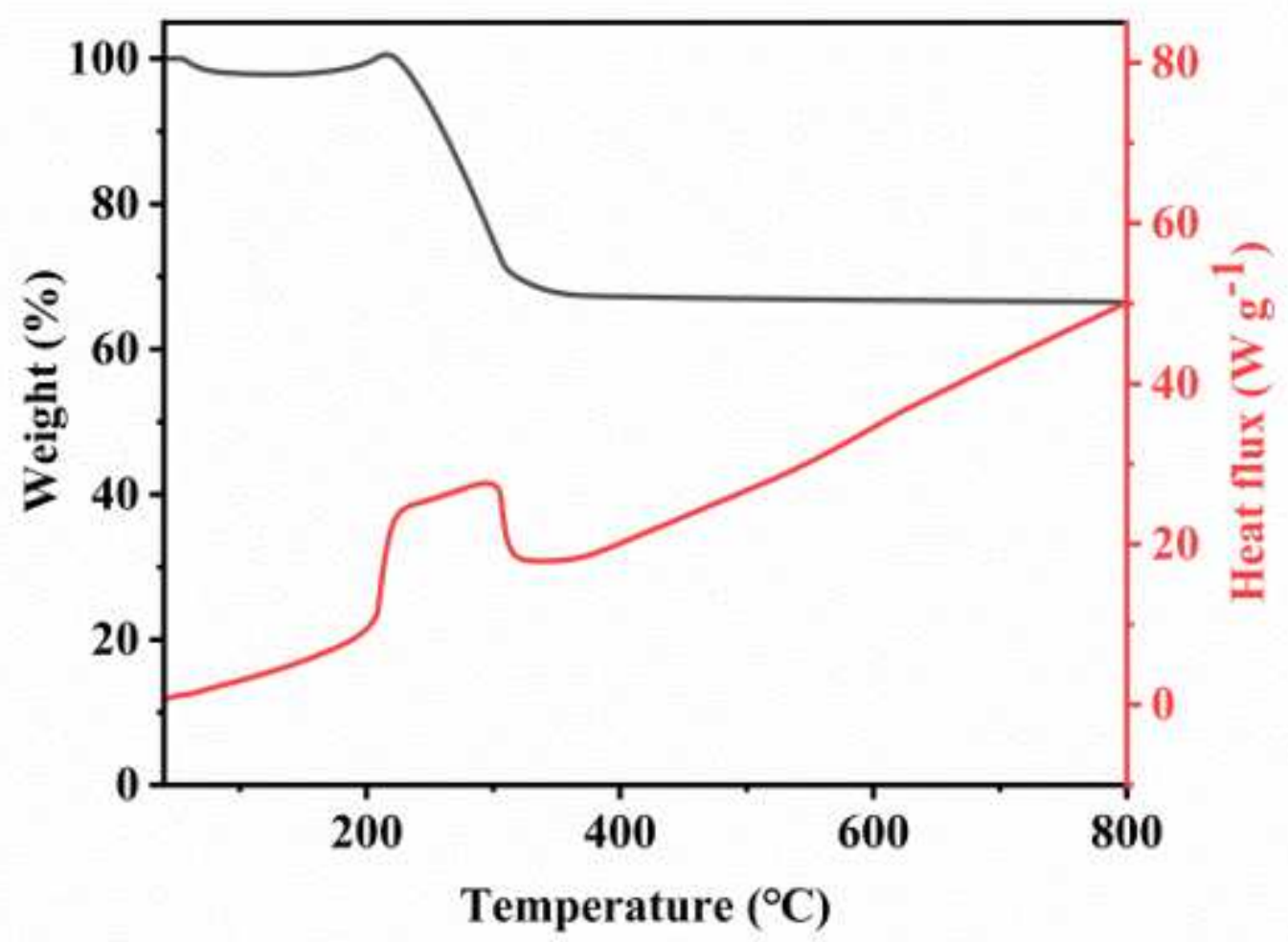

Figure 2

The thermogravimetric analysis (TGA) curves of HCo@NC 

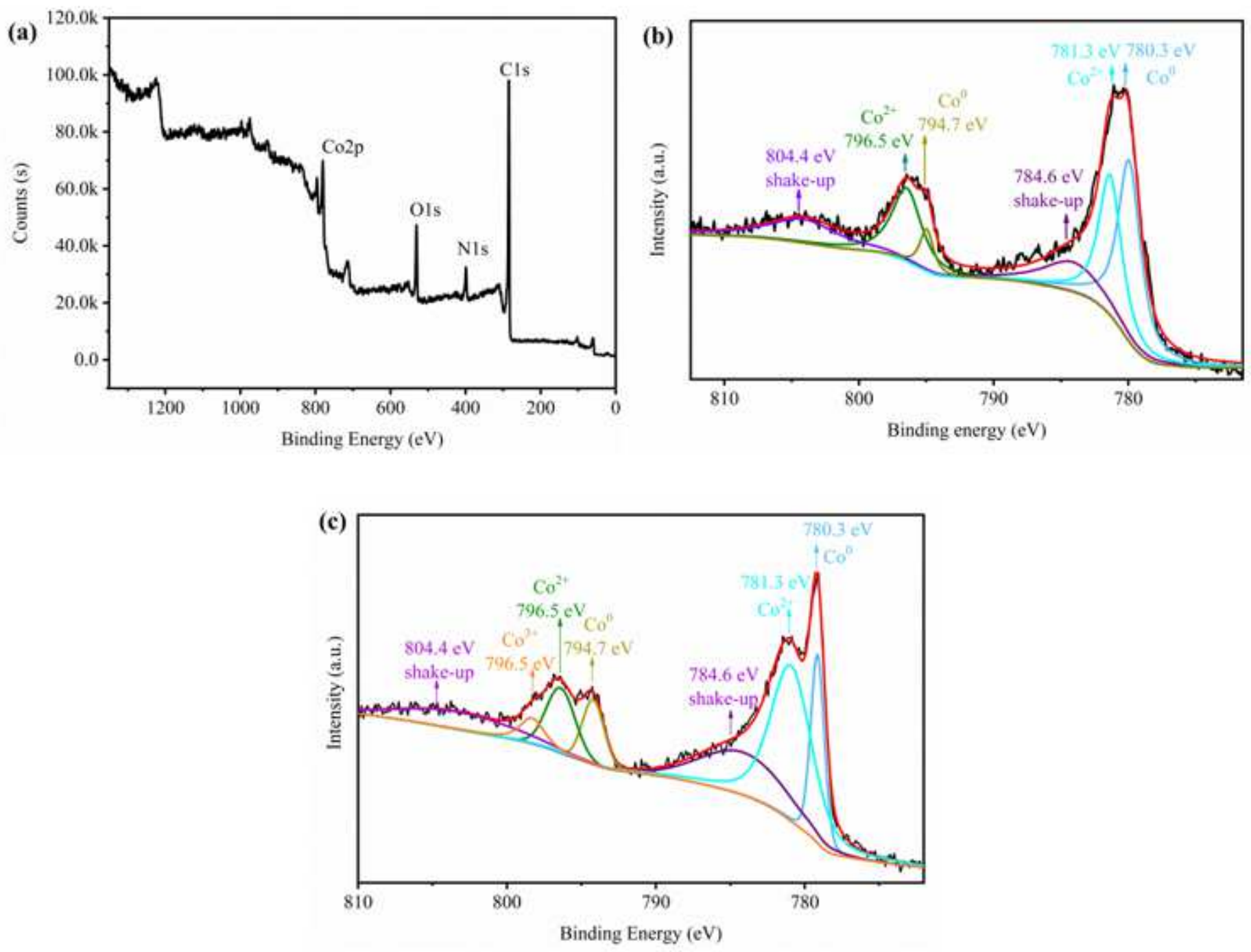

Figure 3

(a) Survey XPS spectra of HCo@NC; (b) Co 2p spectrum of HCo@NC
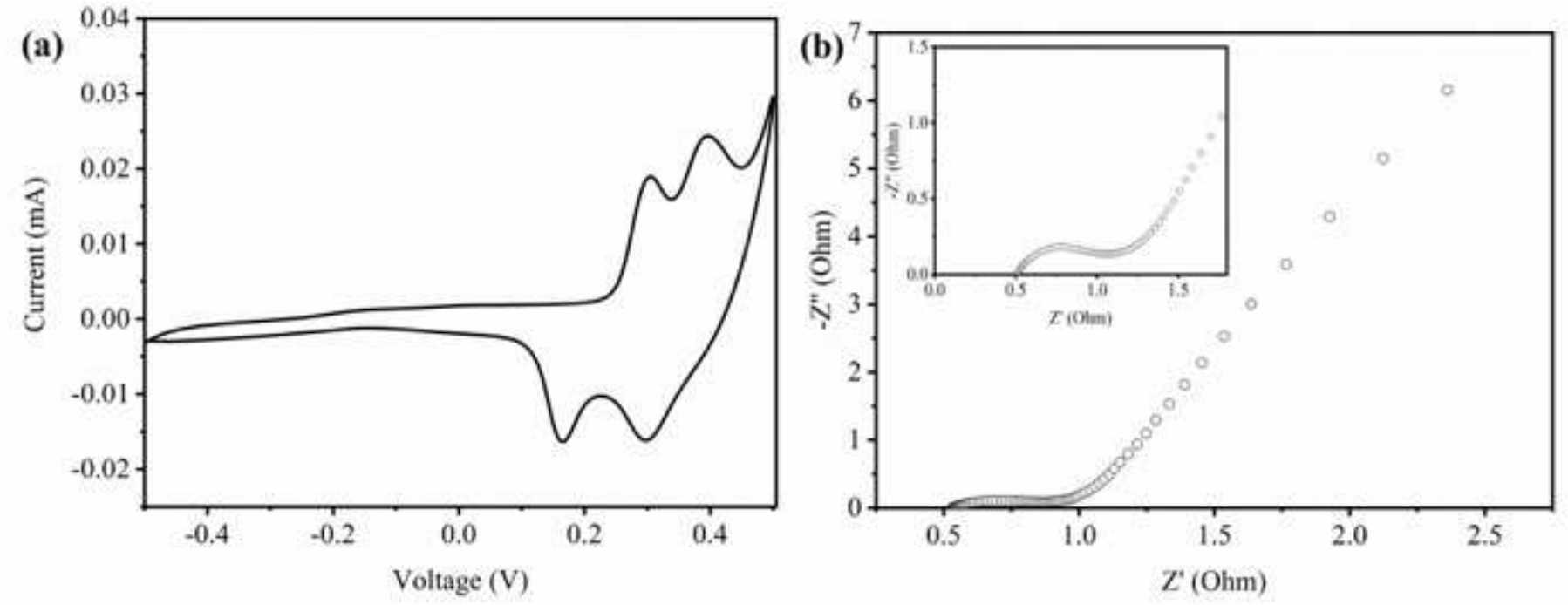
Figure 4

(a) CV curve of HCo@NC at 0.05 mV s-1; (b) EIS spectra of HCo@NC
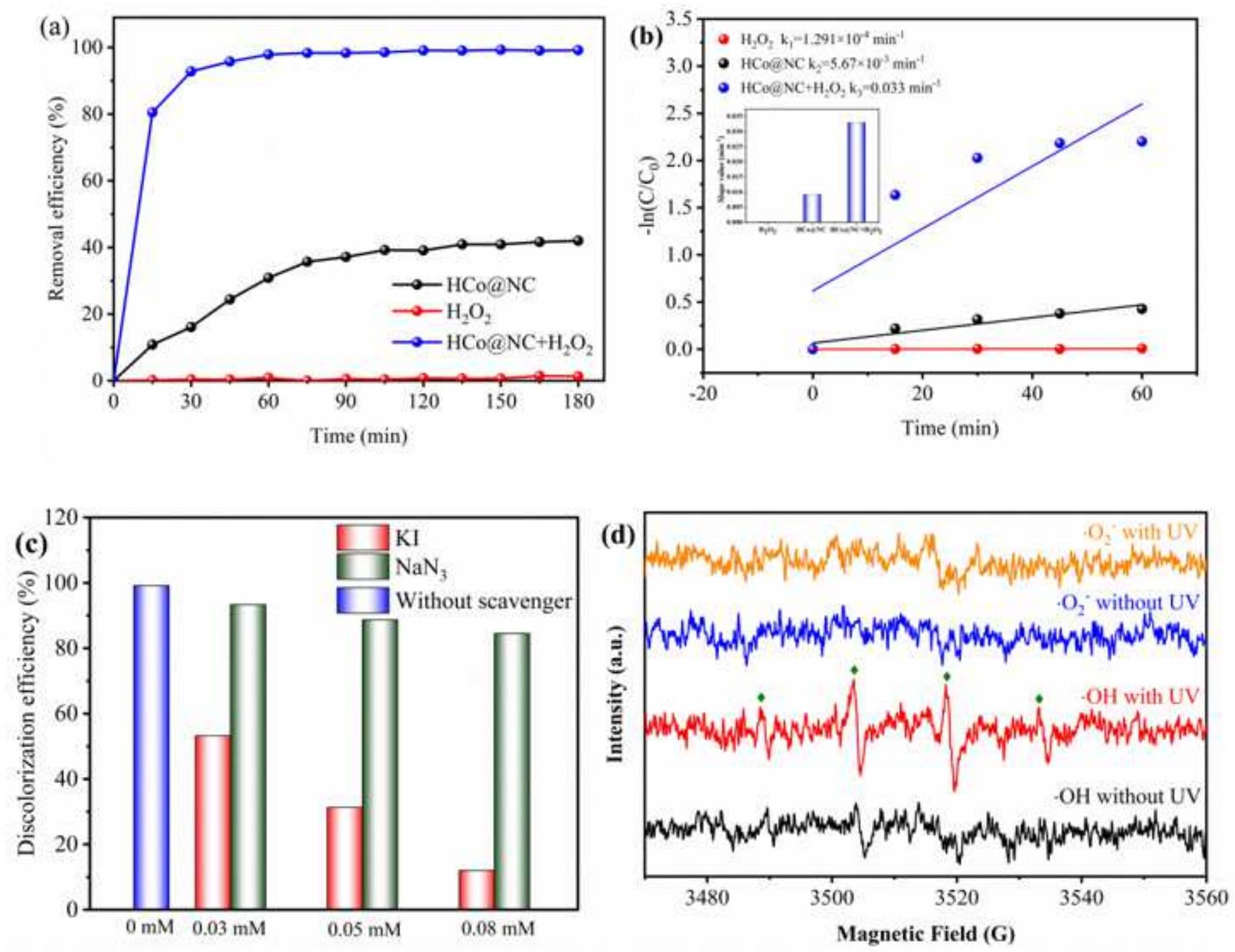

Figure 5

(a) The removal efficiency of TC and (b) the rate constants under different conditions (Reaction condition: $[\mathrm{H} 2 \mathrm{O} 2]=0.71 \mathrm{mmol} \mathrm{L}-1,[\mathrm{TC}]=15 \mathrm{mg} \mathrm{L}-1$, catalyst dosage $=0.03 \mathrm{~g} \mathrm{~L}-1$ and initial $\mathrm{pH}=3$ ); (c) the effects of different scavengers; (d) EPR spectra of H2O2 activation on HCo@NC. 


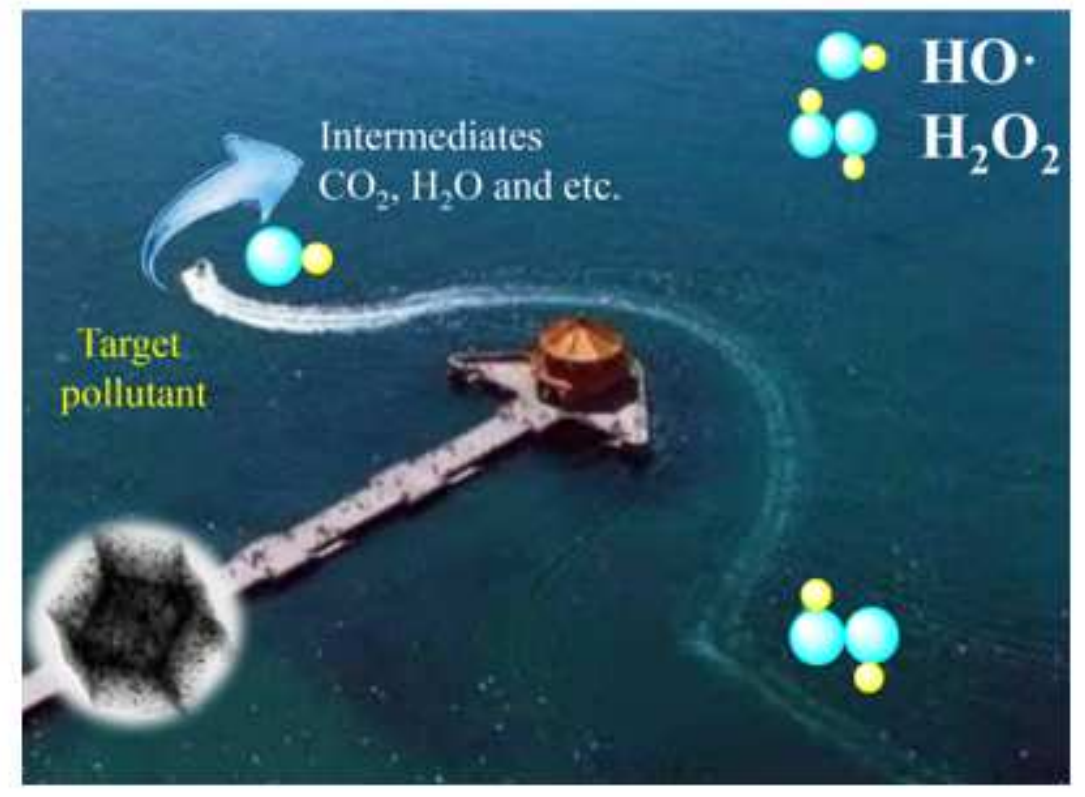

Figure 6

Possible mechanism of Fenton-like system catalyzed by HCo@NC 

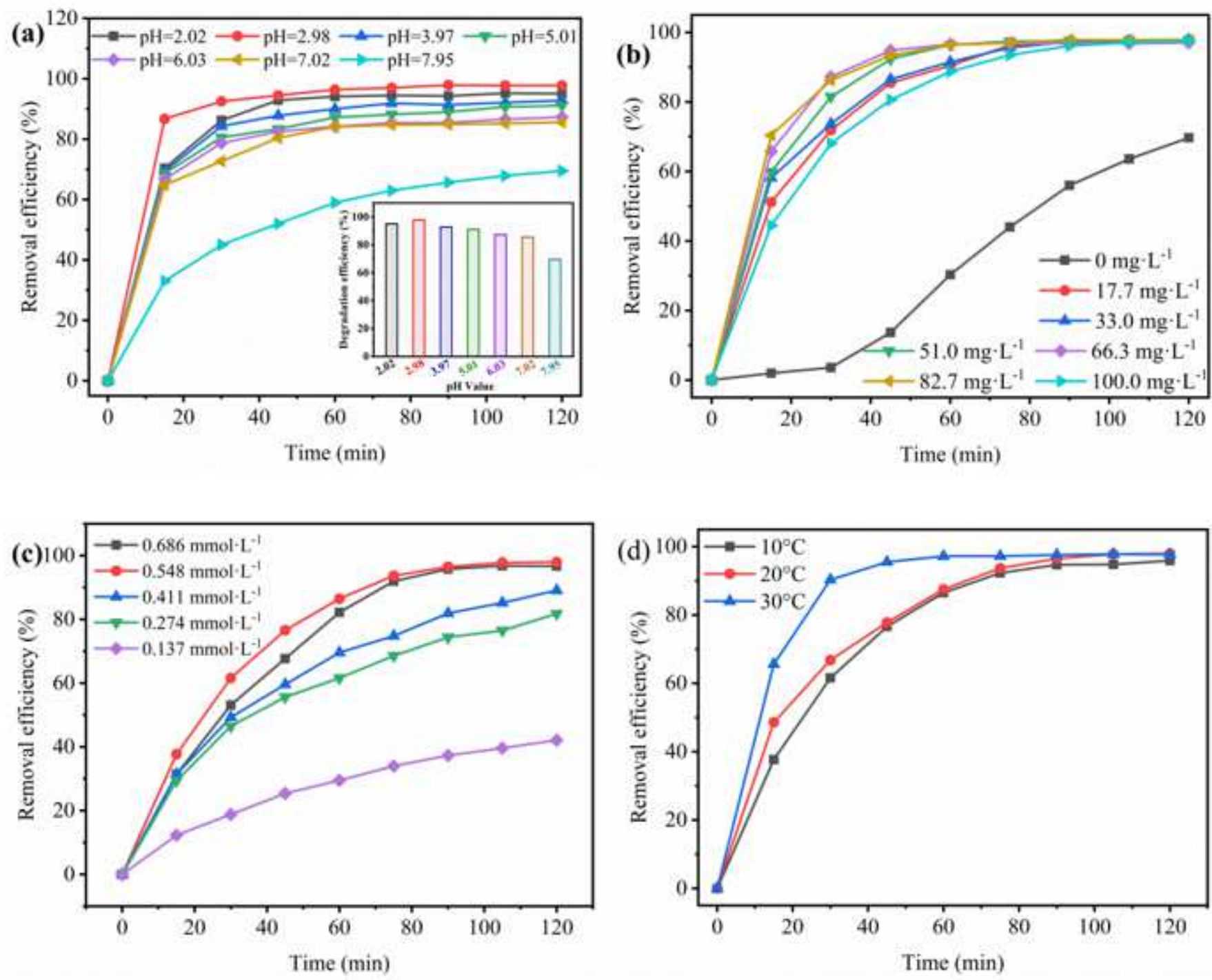

Figure 7

Effects of (a) initial solution pH; (b) dosages of catalyst; (c) dosages of H2O2; (d) temperature on degradation of TC. 


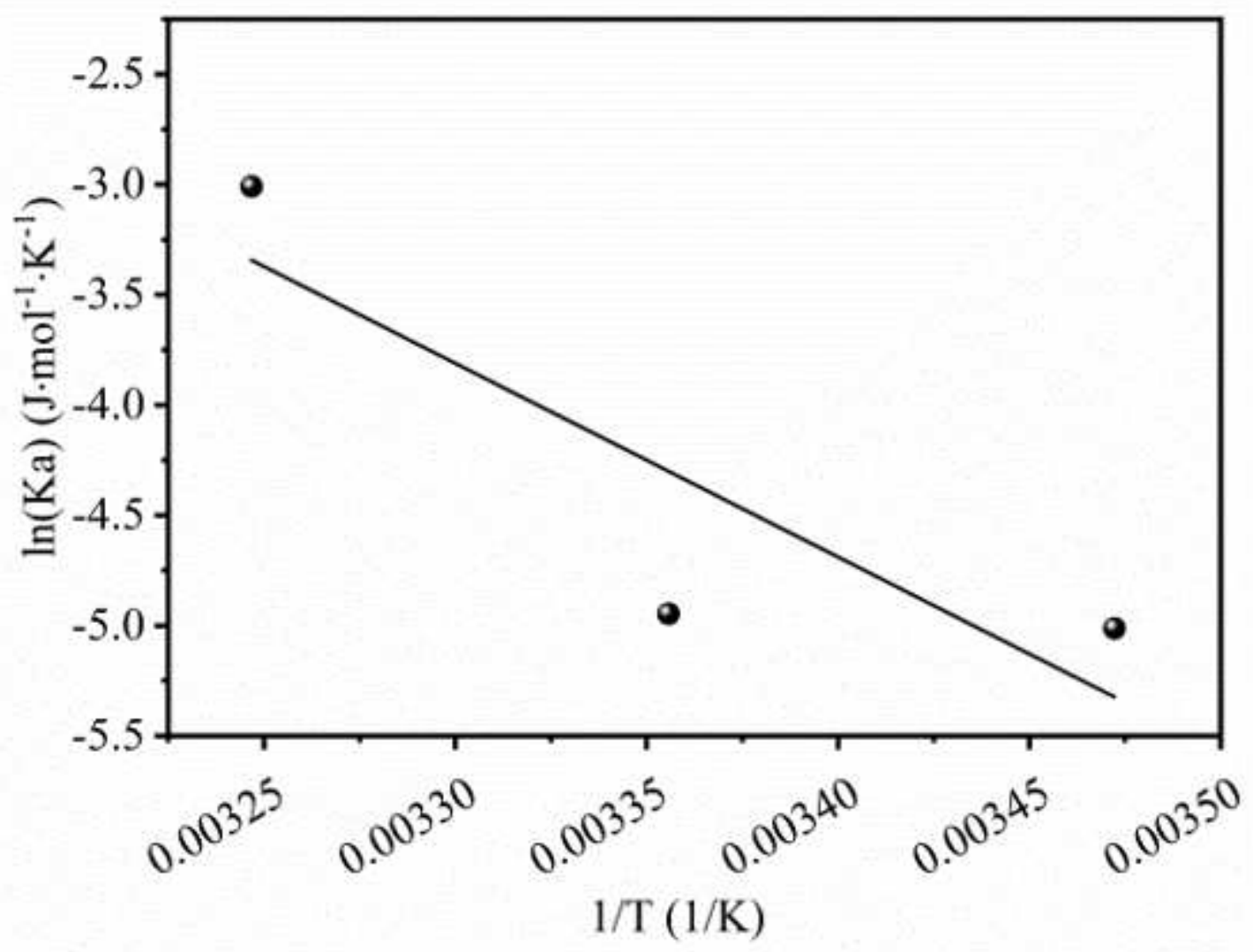

Figure 8

Plot of $\ln (\mathrm{ka})$ versus $1 / \mathrm{T}$ for the estimation of the reaction activated energy

\section{Supplementary Files}

This is a list of supplementary files associated with this preprint. Click to download.

- Scheme1.png

- Fig7graphicalabstract.tif

- highlights.doc 